\title{
Pendampingan Penerapan Model Pembelajaran Sentra Di Gugus PAUD III Kecamatan Pakisaji Kabupaten Malang
}

\author{
Ayu Asmah ${ }^{1}$, Rina Wijayanti ${ }^{2}$ \\ ${ }^{1,2}$ Universitas Kanjuruhan Malang \\ e-mail: ayuasmah@unikama.ac.id
}

\begin{abstract}
The development of learning models at early childhood education is based on the needs and interests of the learners. Learning while playing or playing while learning is the main tenet in developing learning models. The ability of teachers in selecting and implementing the learning models influences learners' behaviors in playing, interecting with peers, and exploring creative activities. The purposes of the present Social Devotion are creating fun activities in learning and suggesting several learning experiences through Sentra Learning Models.The activities presented to the teachers of Gugus PAUD III Pakisaji Region covered 1) coaching on the teories of Sentra Learning Models, 2) coaching on implementing Sentra Learning Models and scheduling the activities of each Sentra, and 3) supervising the implementation of the models in each institution of PAUD. The results of the present social devotion showed that each institution wa able to implemen the models. In addition, it can be concluded that the models not only provide further insights related to the teories of teaching-learning process but also motivate the teachers create better atmosphere of teaching-learning process which cultivates students' development based on the learners' needs and interests.
\end{abstract}

Keyword: coaching;sentra learning models

\section{PENDAHULUAN}

Pengalaman belajar anak usia dini akan bermakna apabila adanya pemberian kesempatan untuk dapat mencoba dan mencari tahu serta membangun pengetahuannya sendiri berdasarkan pengalaman. Lingkungan belajar memberikan pengaruh apa dan bagaimana anak belajar Penataan pembelajaran yang kondusif. dari pendidik yang mengelolaannya, selain itu penataan lingkungan belajar terkait dengan pemilihan model pembelajaran yang diterapkan. Secara umum penataan lingkungan belajar untuk memberikan situasi yang kondusif untuk memfasilitasi perkembangan dan belajar secara optimal.
Salah satu alternatif yang dapat dilakukan adalah melalui pemilihan model pembelajaran yang tepat.Model pembelajaran yang banyak dikembangkan di lembaga pendidikan anak usia dini (PAUD) yaitu model pembelajaran area, sudut, kelompok, dan sentra. Setiap model pembelajaran PAUD memiliki karakteristik yang berbeda.Model pembelajaran sentra merupakan pembelajaran yang berfokus pada anak, berpusat di dalam lingkaran (circle time) dan sentra bermain (Depdiknas, 2008: 52). Model sentra berfungsi sebagai wadah kegiatan bermain anak yang memberikan kesempatan untuk dapat mengembangkan kemampuan dan keterampilan anak melalui bermain tanpa tekanan dan paksaan dari guru dan 
lingkungannya. Selain itu model pembelajaran sentra memiliki ciri khusus yang membedakan dengan model kelompok, area maupun sentra. Ciri dari model pembelajaran sentra adalah: 1) Pemberian pijakan untuk membangun konsep, aturan, ide dan pengetahuan anak, serta konsep densitas dan intesitas bermain; 2) Anak dalam belajar berpusat di sentra bermain dan pada saat anak dalam lingkaran (Sutama dan Budhojo, 2012).

Pijakan dalam model pembelajaran sentra merupakan dukungan yang berubah-ubah untuk menunjang perkembangan anak. Ada empat pijakan yang digunakan dalam pembelajaran sentra anak usia dini yaitu: 1). Pijakan lingkungan main, merupakan tahapan awal dalam mengelola awal lingkungan main dengan bahan-bahan yang cukup, 2). Pijakan pengalaman sebelum main, yaitu pemberian kesempatan pada anak-anak untuk mengenal kosakata baru, berdiskusi tentang tema pembelajaran, mengenal kegaitan main pada hari itu, menyepakati aturan bermain, 3). Pijakan pengalaman main, yaitu memberikan anak waktu untuk mengelola dan memperluas pengalaman main mereka, 4). Pijakan pengalaman setelah bermain, yaitu mendukung anak untuk mengingat kembali pengalaman mainnya dan saling menceritakan pengalaman mainnya.

Hasil observasi di Gugus PAUD III Kecamatan Pakisaji Kabupaten Malang yang terdiri dari enam lembaga yaitu TKM Al Khoiriyah, TKM Nurul Huda, PAUD Wonderful Kids, TKM Siti Khotijah, TK Dharma Wanita Persatuan, dan SPS Melati menunjukkan semua lembaga PAUD dalam proses belajar mengajar telah mengadopsi salah satu model pembelajaran yang sesuai. Model yang diterapkan lembaga mitra yaitu model kelompok dan area. Namun, dalam penerapannya hampir semua lembaga mengarah ke akademik, yaitu cara pembelajaran cenderung membebankan anak didik dengan rangkaian kegiatan yang harus diselesaikan. Kesempatan anak untuk dapat mencari tahu atau bereksplorasi sangat kurang sekali.

Pembelajaran didominasi oleh guru, keaktifan anak hanya pada bentuk menyelesaikan tugas.Permasalahan tersebut disebabkan oleh beberapa hal, yaitu:1) Pengetahuan yang dimiliki oleh guru tentang model pembelajaran terbatas, 2) Pendidik sudah terlalu nyaman dengan model yang konvensional, 3) Penerapan model yang diterapkan tidak sesuai, hanya lebih pada penamaannya saja, 4) Tidak semua SDM yang berada pada lembaga PAUD mitra adalah lulusan dari S-1 PAUD, dan 5) Terbatasnya sarana dan prasarana yang akhirnya menjadi alasan lembaga untuk melakukan pembelajaran yang keluar dari penerapannya.Berdasarkan permasalahan di atas, dibutuhkan solusi inovasi pembelajaran melalui model pembelajaran yang mampu memfasilitasi anak mengembangkan kecakapan berpikir aktif dan memberikan keleluasaan untuk melakukan berbagai kegiatan agar mendapatkan pengalaman tentang dunia sekelilingnya. Model pembelajaran sentra menjadi pemilihan model yang sesuai, karena dalam penerapannya, setiap hari kelompok anak berpindah dari sentra ke sentra lainnya. Pengalaman anak akan beragam, ketika pengalaman mainnya semakin banyak dari masing-masing sentra. Elemen penting yang menjadi sifat model pembelajaran sentra adalah pembelajaran yang non-direct teaching atau tidak menggurui anak (Latif dkk. 2013: 105).

\section{METODE KEGIATAN}

Metode yang dilaksanakan untuk mengatasi permasalahan mitra adalah sebagai berikut: 
a. Pemberian materi tentang model pembelajaran sentrapada anak usia dini.

b. Pelatihan implementasi model pembelajaran sentra dan penyusunan rencana kegiatan pada masing-masing sentra pendidikan PAUD.

c. Pendampingan penerapan model pembelajaran sentra pada masing-masing lembaga penyelenggara pendidikan anak usia dini.

\section{HASIL DAN PEMBAHASAN}

Penataan lingkungan belajar yang menyenangkan di lembaga PAUD dirancang agar anak secara aktif beraktivitas dalam menumbuhkan kemampuannya sesuai dengan bakat dan minatnya. Tanggungjawab penataan lingkungan belajar bagi anak-anak di PAUD merupakan tanggungjawab pendidik. Pendidik sebagai ujung tombak dalam penyediaan lingkungan belajar yang kondusif. Keterampilan pendidik dalam menyediakan lingkungan belajar berpengaruh terhadap kegiatan anak-anak baik dalam bermain, berinteraksi, bereksperimen, bereksplorasi dan kegiatan kreatif lainnya.Pendidik di Gugus PAUD III Kecamatan Pakisaji Kabupaten Malang, selama ini kurang mendapatkan sosialisasi bagaimana menciptakan lingkungan belajar yang dapat memfasilitasi kebutuhan dan minat anak serta kegiatan yang menyenangkan dan dapat mendukung keaktifan anak. Pendidik PAUD sangat membutuhkan penyegaran sebagai bentuk inovasi pembelajaran agar dapat menyediakan lingkungan belajar yang kondusif dan menyenangkan bagi anak-anak.

Solusi yang diberikan kepada mitra di Gugus PAUD III Kecamatan Pakisaji Kabupaten Malang yaitu dengan melakukan kegiatan pendampingan pembelajaran dengan menggunakan model pembelajaran sentra. Rangkaian kegiatan pengabdian di Gugus
PAUD III Kecamatan Pakisaji Kabupaten Malang, yaitu:

1. Pemberian materi tentang model pembelajaran sentra

Gugus PAUD IIIKecamatan Pakisaji selama ini hanya pernah mendapatkan materi tentang model pembelajaran sentra, namun tidak dengan implementasinya. Sehingga, bagi lembaga yang ingin merubah ke model sentra masih kesulitan bagaimana menerapkannya. Lembaga-lembaga tersebut selama ini juga melakukan kunjungan atau studi banding ke lembaga PAUD yang sudah menerapkan model sentra, namun tidak mengerti bagaimana cara pengelolaan pembelajarannya.

Memahami permasalahan ini, maka pengabdi berupaya melakukan kegiatan yang bertujuan untuk memberikan wawasan kepada pendidik PAUD di Gugus PAUD Kecamatan Pakisaji tentang model pembelajaran sentra. Materi yang diberikan berkaitan dengan apa itu model pembelajaran sentra, pijakan model pembelajaran sentra, jenis sentra main, dan penerapan model pembelajaran sentrapada anak usia dini.

2. Pelatihan implementasi model pembelajaran sentra

Implementasi model pembelajaran sentra dilakukan dengan melakukan secara langsung bagaimana proses belajar di sentra. Pengabdi berperan sebagai guru sentra dan guru-guru Gugus PAUD III Kecamatan Pakisaji berperan sebagai anak didik. Implementasi dilakukan sesuai dengan rangkaian pembelajaran sentra.

Kegiatan implementasi dimulai di sentra persiapan dengan diawali dari pijakan awal yaitu pijakan lingkungan dimana pendidik menyiapkan lingkungan belajar anak sesuai dengan sentra. Kemudian dilanjutkan circle time sebelum anak masuk ke dalam kelas, yaitu kegiatan bernyanyi, senam/menari, permainan yang biasanya dilakukan di halaman sekolah 
oleh seluruh anak didik pada sekolah yang bersangkutan.Setelah kegiatan circle time dilanjutkan anak-anak dipersilahkan ke sentra sesuai jadwal pada hari itu. Selanjutnya pijakan lingkungan sebelum main, yaitu kegiatan awal atau pembukaan.

Awal kegiatan anak diajak membuat circle untuk berdoa, membahas tema, mengenalkan kosakata baru, menyampaikan kegiatan di sentra main (kegiatan inti) dan aturan main.Sebelum ke pijakan bermain ada jeda waktu atau transisi selama \pm 5 menit. Hal ini untuk memberikan kesempatan kepada anak minum ataupun ke kamar mandi. Pijakan selanjutnya yaitu pijakan saat bermain, di pijakan ini anak melakukan kegiatan sesuai dengan sentra. Anak didik dapat secara bergantian melakukan aktivitas sesuai dengan destinasi kegiatan yang disediakan oleg guru sentra.



Gambar 1. Pemberian Materi Model Pembelajaran Sentra

Kegiatan di akhiri dengan pijakan setelah bermain yaitu kesempatan bagi guru untuk mereview kegiatan anak didik di saat pijakan main. Guru mengulas dan melakukan tanya jawab atas apa yang telah dilakukan oleh anak didik. Posisi duduk guru dan anak didik tetap dalam bentuk lingkaran pada saat pijakan setelah bermain. Setelah itu dilanjutkan istirahat. Akhir kegiatan yaitu penutup yang dilakukan dengan melakukan kegiatan bercerita, mereview kegiatan dari awal kegiatan sampai dengan akhir, dan diakhiri dengan berdoa.

3. Penyusunan rencana kegiatan pada masingmasing sentra

Tahap selanjutnya yaitu, pengabdi memberikan pelatihan untuk membuat rencana pelaksanaan pembelajaran mingguan (RPPM) dan rencana pelaksanaan pembelajaran harian (RPPH). Penyusunan rancangan pembelajaran dibagi menjadi beberapa kelompok yaitu kelompok sentra balok, sentra persiapan, sentra alam, sentra seni dan sentra bermain peran.

4. Pendampingan penerapan model pembelajaran sentra pada masing-masing lembaga.

Rangkaian terakhir dari kegiatan pengabdian adalah melakukan pendampingan penerapan model pembelajaran sentra di lembaga Gugus PAUD III Kecamatan Pakisaji Kabupaten Malang. Kegiatan di masing-masing lembaga dilakukan selama 1 minggu. Pendampingan dilakukan mulai dari penataan ruangan sentra, membuat RPPM dan RPPH, praktek pembelajaran sentra yang dilakukan selama 3 hari. Penataan ruangan disesuaikan dengan sentra yang dipilih oleh masing-masing lembaga. Sentra yang disediakan juga disesuaikan dengan jumlah ruangan, sarana dan prasarana.

Praktek awal dilakukan oleh pendamping sebagai guru dan guru di lembaga 
sebagai anak didik. Hari kedua dan ketiga implementasi model pembelajaran sentra langsung dilakukan pada anak didik. Kegiatan dimulai dari circle time bersama di halaman sekolah dan dilanjutkan di dalam kelas.

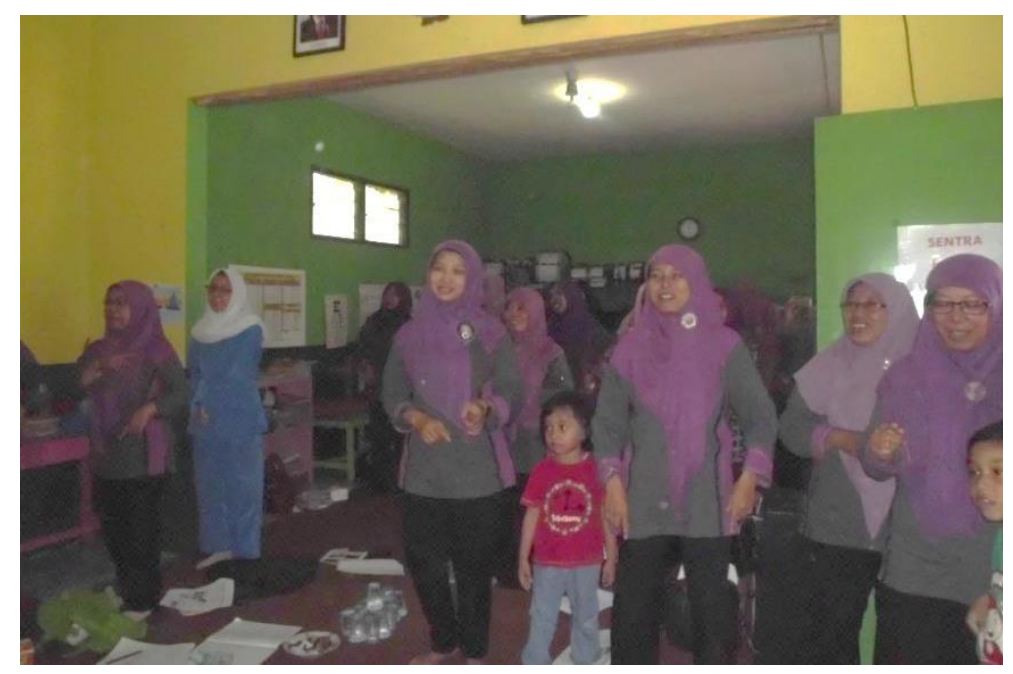

Gambar 3. Kegiatan circle time sebelum masuk ke sentra

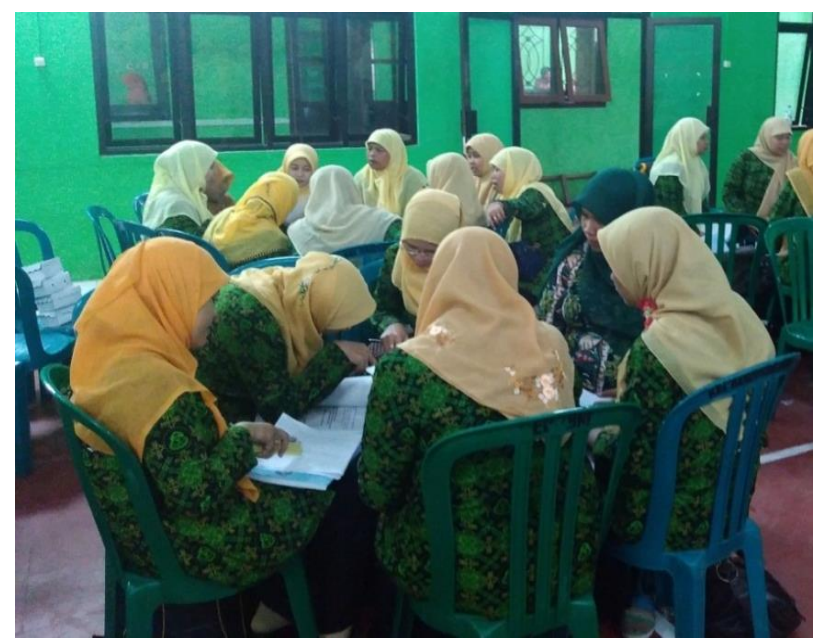

Gambar 4. Penyusunan RPPH berkelompok berdasarkan sentra

\section{III.KESIMPULAN}

Program Pengabdian Kepada

Masyarakat ini menekankan pada penerapan model pembelajaran sentra, yaitu model pembelajaran yang berfungsi sebagai wadah kegiatan bermain anak dengan memberikan kesempatan untuk dapat mengembangkan kemampuan dan keterampilan anak melalui bermain tanpa tekanan dan paksaan dari guru dan lingkungannya. Materi dan cara

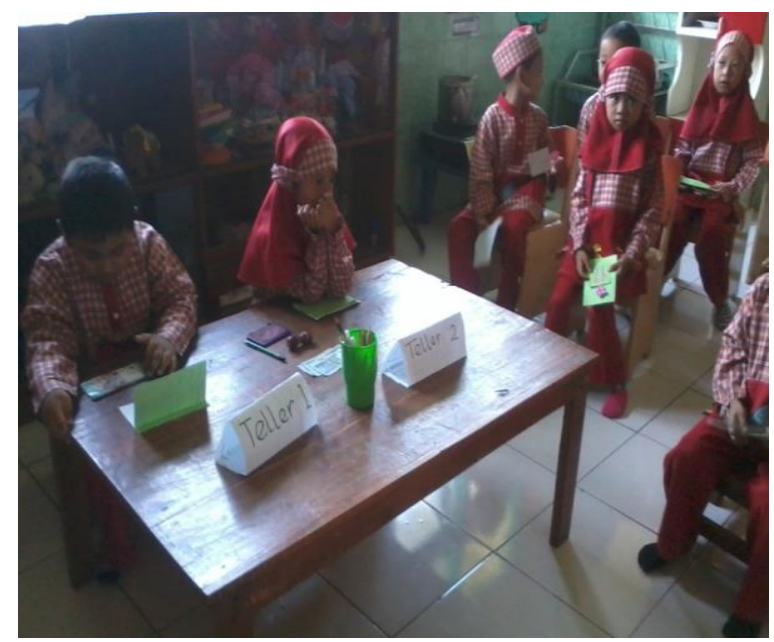

Gambar 5. Implementasi saat pendampingan model pembelajaran sentra

mengimplementasikan model pembelajaran sentra yang sudah disosialisasikan diharapkan dapat memotivasi lembaga di Gugus PAUD III Kecamatan Pakisaji Kabupaten Malang dalam menciptakan lingkungan belajar yang dapat mendukung perkembangan anak sesuai dengan bakat dan kebutuhannya. 


\section{IV.TERIMA KASIH}

Tim pengabdi mengucapkan terima kasih kami sampaikan kepada:

1. LPPM Universitas Kanjuruhan Malang, atas pemberian dana program pengabdian masyarakat tahun anggaran 2017 sehingga program ini telah dapat kami laksanakan dengan sebaik-baiknya

2. Ketua Gugus PAUD III Kecamatan Pakisaji Kabupaten Malang yang telah memberikan kesempatan pengabdi untuk melakukan pengabdian ini.

3. Lembaga PAUD yang berada di Gugus PAUD III Kecamatan Pakisaji Kabupaten Malang yang telah berkenan bekerjasama untuk mengembangkan model pembelajaran sentra.

\section{DAFTAR PUSTAKA}

Departemen Pendidikan Nasional, 2008. Pengembangan Model Pembelajaran. Jakarta: Departemen Pendidikan Nasional.

Latief, M., Zukhairina, Zubaidah, R., dan Afandi, M.2013.Orientasi Baru Pendidikan Anak Usia Dini. Jakarta: Kencana Prenada Media Group.

Sutama, W. dan Budhojo, K. 2012. Model Pembelajaran PAUD. Malang: Universitas Negeri Malang. 